\title{
Examining an Effective Way to Support Vulnerable Road Users in Itsukaichi District, Hiroshima City
}

\author{
Shimpei Matsumoto ${ }^{*}$, Nobuyuki Ohigashi ${ }^{\dagger}$
}

\begin{abstract}
Hiroshima City is surrounded by mountains on its three sides, the east, north, and west, except the south facing the sea, and besides, its urban area places delta region. The capacity of the urban area in Hiroshima City is limited, so its land prices are exceedingly higher than other areas. Due to these conditions, most of the residents live in residential estates at the slope of these mountains surrounding the city. However, the living environment of the suburban slope residential estates doesn't seem so suitable for vulnerable road users, mainly elderly people. Thus in this paper, based on the investigation results of residents' traffic attitude in the slope residential estates at Itsukaichi district, Hiroshima City, we examine an effective way to support vulnerable road users and to enrich their life. Especially, we show an concept of information sharing system to support the transportation of residents living in a place where public transportation is not sufficiently developed.
\end{abstract}

Keywords: Hiroshima City, Transportation support, Vulnerable road users, Move-sharing

\section{Introduction}

Hiroshima City is surrounded by mountains on its three sides, the east, north, and west, except the south facing the sea, and besides, its urban area places delta region. The area of the urban area in Hiroshima City is limited, so the land prices near the urban area are exceedingly higher than common urban area in Japan. Due to these conditions, the majority of the population is concentrated in the slope residential estates at the surrounding mountains of the city. However, as Japan's population decreases and the society ages, the living environment of the suburban slope residential estates doesn't seem so suitable for vulnerable road users, mainly elderly people. Concretely, since the residential land development was completed in the suburban residential areas, sometimes disappearance of commercial function (withdraw of commercial center) was found due to various factors such as population outflow and aging. Most of these residential areas had been developed under the theory of neighborhood unit [1], but their structure have changed into a surrounding that cannot provide commercial services within walking distance, and eventually, traffic convenience in these areas has declined. In the case of housing estates developed at suburban slope area,

* Hiroshima Institute of Technology, Hiroshima, Japan

$\dagger$ Hiroshima Institute of Technology, Hiroshima, Japan 
originally using a bicycle is often difficult. Besides, footing from each resident's house to a base such as a bus stop has also probably been difficult because of aging even though there are some public transportations. Unlike flat residential area, perhaps the degrees of traffic convenience of housing estates at slope area are widely different depending on locational conditions such as the distance to bus stop and with/without private cars. Now, with the downward turn of the population, the local government of these surroundings should address against aging to improve the traffic convenience of public transportation by effectively utilizing resident's private car and keep the residents at slope area for the longest possible time.

In this study, based on the investigation result of residents' traffic awareness [2] in the slope residential areas at Itsukaichi district, a main bedroom suburb of Hiroshima City, we embody the concept [3], a transportation support model for residents living in a place where public transportation service is not sufficiently provided, and propose a concept of Web service. The main aim of the transportation support model is to help the everyday life of vulnerable road users, mainly elderly people with the cooperation of local community residents. We have considered that an efficient method to embody the idea of transportation support model would be the sharing of each resident's schedule to move with Web technology. Thus, the core service of the proposed system is designed to enhance the encounter between local people which is created by the above schedule sharing and will lead to a troubled resident's problem related to the movement. In this paper, we call this encounter as "move-sharing", so we can understand that the proposed system is to provide the opportunity of move-sharing with Web technology as the main service and to support the transportation of local community residents. To enhance move-sharing, the proposed system provides primary two services, the negotiation support, and the schedule sharing, and they will support the cooperation between local community residents easily. Concretely, these functions of the proposed system facilitate someone's request and acceptance of the transportation and creates the opportunity of move-sharing such as ride-sharing from a residential area to a city center. With the proposed system, a resident, who will move to his/her destination by one's transportation mean (a motorcycle or a car), can fulfill another resident's demand on a move with his/her original objective together. As the kinds of the demands, there will be not only ride-sharing with a resident's private transportation means, but also the conveyance of luggage from residential areas to a place near another resident's destination or vice versa. The move-sharing generated by the proposed system is expected to enhance people's relationship building and the regeneration of local community.

This paper firstly mentions the current situation of Itsukaichi district and the summary of survey result on traffic awareness [2], and after shows the detailed explanation and further discussions about our conception, the parts of which were already mentioned by our previous work [4].

\section{Itsukaichi District, Hiroshima City}

Itsukaichi district, the target region of this study, is a major bedroom suburb of Hiroshima City as shown in Fig. 1. In itsukaichi district, there are some housing estates systematically developed. The old housing estates among these were built more than 30 years ago, and over 20 years have passed after these sales even the new housing estates. A lot of families moved into these housing estates at the same time with these sales, so there are more people in a certain age group than other age groups. Many residents are going to retire in the near 


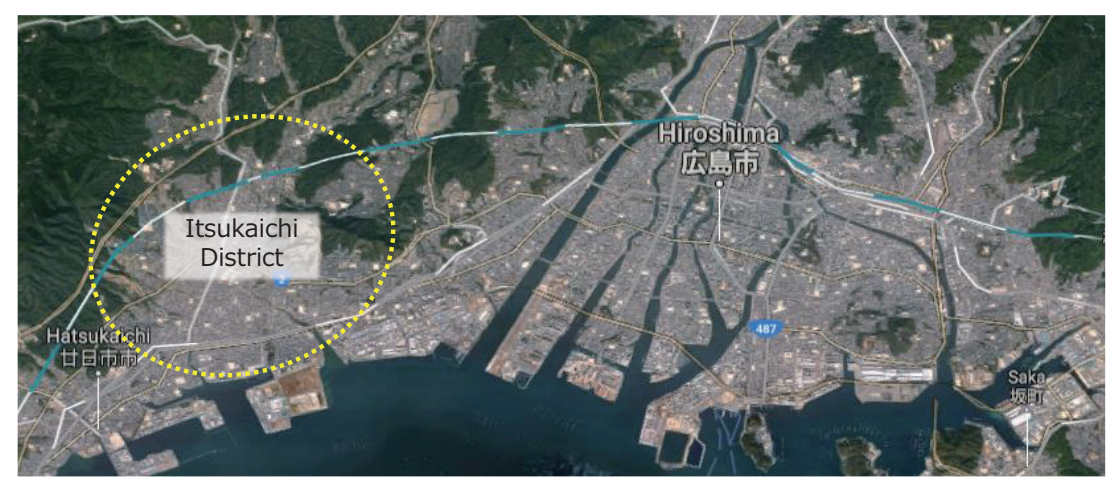

Figure 1: Itsukaichi district

Table 1: Summary of residential areas targetted by this study

\begin{tabular}{|c|c|c|c|}
\hline Region & Misuzugaoka housing estate & Ayagaoka housing estate & Ishiuchi region \\
\hline Beginnings & $\begin{array}{l}\text { Systematically developed } \\
\text { new towm }\end{array}$ & $\begin{array}{l}\text { Systematically developed } \\
\text { new towm }\end{array}$ & Old standing settlement \\
\hline Houses & 3626 & 1250 & 520 \\
\hline Population & ca. 11000 & ca. 4500 & ca. 1800 \\
\hline Areas & 4 & 2 & 9 \\
\hline Sales year & 1978 & 1992 & $\mathrm{n} / \mathrm{a}$ \\
\hline
\end{tabular}

Table 2: Conditions of the questionnaire survey

\begin{tabular}{l|lll}
\hline Region & Misuzugaoka housing estate & Ayagaoka housing estate & Ishiuchi region \\
\hline Period & April - early July, 2006 & Dec. 2006 - early Feb. 2007 June - late August, 2007 \\
Circulation & 3626 (all households) & 1250 (all households) & 520 (all households) \\
Collection & 2105 & 522 & 324 \\
Collection ratio & $58.10 \%$ & $41.76 \%$ & $62.30 \%$ \\
\hline
\end{tabular}

future even in the new housing estates. These housing estates are far from the central area and inconvenient for people who cannot freely use his/her private car. Additionally, footing and the use of bicycle are not easy because most of these housing estates are at the slope area at the surrounding mountains of the city. Therefore, some of them already emigrated from theses housing estates to apartment buildings in central areas which are convenient for shopping and transportation for elderly people.

Meanwhile, there are also some old standing settlements in Itsukaichi district where a majority of residents in these settlements are already aging. Each settlement has a minimum number of retail stores providing daily necessaries, so these residents can get a minimum of daily necessaries within their region. On the other hand, their commuting and other shopping to the central area depend on only motor movement including bus and private car, but there are few major roads. Then, traffic jams often occur because automobiles concentrate on the limited major roads. These situations would be the firm evidence of the low service level on transportation and would indicate that it is difficult to keep these settlements as a residential district.

A total population of Hiroshima City is already beginning to decrease. Then, the competition between these residential areas and others including downtown apartments is going to start. To keep competitiveness as a residential area, even systematically developed 
Table 3: Ratios of daily transportation means in each residential area

\begin{tabular}{l|llllll}
\hline Residential Area & \multicolumn{2}{|l}{ Misuzugaoka housing estate } & \multicolumn{2}{l}{ Ayagaoka housing estate } & \multicolumn{2}{l}{ Ishiuchi region } \\
\hline Subject & $\begin{array}{l}\text { Senior } \\
(\mathrm{n}=642)\end{array}$ & $\begin{array}{l}\text { Non- } \\
\text { senior } \\
(\mathrm{n}=1357)\end{array}$ & $\begin{array}{l}\text { Senior } \\
(\mathrm{n}=91)\end{array}$ & $\begin{array}{l}\text { Non- } \\
\text { senior } \\
(\mathrm{n}=414)\end{array}$ & $\begin{array}{l}\text { Senior } \\
(\mathrm{n}=145)\end{array}$ & $\begin{array}{l}\text { Non- } \\
\text { senior } \\
(\mathrm{n}=156)\end{array}$ \\
\hline Walk & $15.4 \%$ & $17.3 \%$ & $0.4 \%$ & $0.5 \%$ & $1.2 \%$ & $3.0 \%$ \\
Bicycle & $1.6 \%$ & $1.4 \%$ & $0.3 \%$ & $1.5 \%$ & $9.4 \%$ & $7.2 \%$ \\
Own private car & $52.6 \%$ & $59.7 \%$ & $75.3 \%$ & $85.1 \%$ & $59.3 \%$ & $73.8 \%$ \\
Another's private car & $19.2 \%$ & $11.7 \%$ & $13.4 \%$ & $8.8 \%$ & $18.3 \%$ & $7.0 \%$ \\
Taxi & $1.0 \%$ & $0.2 \%$ & $0.4 \%$ & $0.0 \%$ & $0.0 \%$ & $0.0 \%$ \\
Bus & $8.0 \%$ & $6.7 \%$ & $7.2 \%$ & $2.0 \%$ & $7.3 \%$ & $6.9 \%$ \\
Other & $2.2 \%$ & $3.0 \%$ & $3.0 \%$ & $2.1 \%$ & $4.5 \%$ & $2.1 \%$ \\
\hline
\end{tabular}

Table 4: Satisfaction level with transportation in each residential area

\begin{tabular}{l|llllll}
\hline Residential Area & \multicolumn{2}{|l}{ Misuzugaoka housing estate } & \multicolumn{2}{l}{ Ayagaoka housing estate } & \multicolumn{2}{l}{ Ishiuchi region } \\
\hline Subject & $\begin{array}{l}\text { Senior } \\
(\mathrm{n}=655)\end{array}$ & $\begin{array}{l}\text { Non- } \\
\text { senior } \\
(\mathrm{n}=1387)\end{array}$ & $\begin{array}{l}\text { Senior } \\
(\mathrm{n}=98)\end{array}$ & $\begin{array}{l}\text { Non- } \\
\text { senior } \\
(\mathrm{n}=413)\end{array}$ & $\begin{array}{l}\text { Senior } \\
(\mathrm{n}=155)\end{array}$ & $\begin{array}{l}\text { Non- } \\
\text { senior } \\
(\mathrm{n}=149)\end{array}$ \\
\hline Satisfied & $12.7 \%$ & $16.2 \%$ & $2.7 \%$ & $4.1 \%$ & $3.2 \%$ & $2.8 \%$ \\
Somewhat satisfied & $36.1 \%$ & $39.7 \%$ & $19.3 \%$ & $26.1 \%$ & $7.0 \%$ & $6.8 \%$ \\
Somewhat unsatisfied & $34.0 \%$ & $31.1 \%$ & $43.2 \%$ & $39.1 \%$ & $16.6 \%$ & $28.0 \%$ \\
Unsatisfied & $17.2 \%$ & $13.0 \%$ & $34.8 \%$ & $30.7 \%$ & $73.2 \%$ & $62.4 \%$ \\
\hline
\end{tabular}

housing estates which are now providing some kind of public transportation will have to enhance the service level by introducing further accessible public transportation. Especially, the service level of public transportation should be improved before most residents age like the old standing settlements. Concretely, we have considered that the public transportation in these residential areas should include a service level accessible by walk from each resident's house without burden based on the consideration from the interview with local governments/citizens groups and also the examination of the current situation of public transportation at each residential area.

\section{Summary of Survey Result}

The authors investigated the actual situation of transportation from the questionnaire for some regional districts and clarified what is desired from local people to routinely move for short-distance rides mainly shopping [2]. Three residential areas, Misuzugaoka housing estate, Ayagaoka housing estate, and Ishiuchi region were targetted by our study (see Table 1). This questionnaire was composed of some items to investigate the actual situation and needs for transportation means. The investigation items were as follows: personal attributes such as age, gender, and family composition of questionee, the presence of driver's license, possession situation of private cars, means of daily move (a private car or public transportation) for shopping (a place and its frequency), questionee's awareness about the current public transportation (have been satisfied/unsatisfied, and its reason). The conditions of the questionnaire survey, such as schedule, circulation and collection ratio are shown in Table 2. The questionnaires were circulated to all households through community associations in each residential area and collected. Thanks to the cooperation of each community associa- 
Table 5: Solution approach to unsatisfaction in transportation

\begin{tabular}{l|llllll}
\hline Residential Area & \multicolumn{2}{|l}{ Misuzugaoka housing estate } & \multicolumn{2}{l}{ Ayagaoka housing estate } & \multicolumn{2}{l}{ Ishiuchi region } \\
\hline Subject & $\begin{array}{l}\text { Senior } \\
(\mathrm{n}=662)\end{array}$ & $\begin{array}{l}\text { Non- } \\
\text { senior } \\
(\mathrm{n}=1397)\end{array}$ & $\begin{array}{l}\text { Senior } \\
(\mathrm{n}=97)\end{array}$ & $\begin{array}{l}\text { Non- } \\
\text { senior } \\
(\mathrm{n}=416)\end{array}$ & $\begin{array}{l}\text { Senior } \\
(\mathrm{n}=163)\end{array}$ & $\begin{array}{l}\text { Non- } \\
\text { senior } \\
(\mathrm{n}=158)\end{array}$ \\
\hline Increasing bus service & $37.1 \%$ & $35.3 \%$ & $53.0 \%$ & $45.4 \%$ & $78.0 \%$ & $73.0 \%$ \\
Increasing bus stop & $13.1 \%$ & $11.0 \%$ & $3.2 \%$ & $2.8 \%$ & $8.2 \%$ & $5.8 \%$ \\
Reduction in bus fare & $37.9 \%$ & $36.8 \%$ & $33.6 \%$ & $38.7 \%$ & $9.1 \%$ & $5.2 \%$ \\
Reduction in taxi fare & $8.2 \%$ & $6.4 \%$ & $3.9 \%$ & $4.1 \%$ & $3.5 \%$ & $3.1 \%$ \\
Other & $3.7 \%$ & $10.5 \%$ & $6.3 \%$ & $9.0 \%$ & $1.2 \%$ & $12.9 \%$ \\
\hline
\end{tabular}

Table 6: Interest in a community-based new transportation mean

\begin{tabular}{|c|c|c|c|c|c|c|}
\hline Residential Area & \multicolumn{2}{|c|}{ Misuzugaoka housing estate } & \multicolumn{2}{|c|}{ Ayagaoka housing estate } & \multicolumn{2}{|c|}{ Ishiuchi region } \\
\hline Subject & $\begin{array}{l}\text { Senior } \\
(\mathrm{n}=653)\end{array}$ & $\begin{array}{l}\text { Non- } \\
\text { senior } \\
(n=1391)\end{array}$ & $\begin{array}{l}\text { Senior } \\
(\mathrm{n}=94)\end{array}$ & $\begin{array}{l}\text { Non- } \\
\text { senior } \\
(n=416)\end{array}$ & $\begin{array}{l}\text { Senior } \\
(\mathrm{n}=160)\end{array}$ & $\begin{array}{l}\text { Non- } \\
\text { senior } \\
(n=155)\end{array}$ \\
\hline Use always & $10.4 \%$ & $15.8 \%$ & $8.2 \%$ & $16.3 \%$ & $18.6 \%$ & $16.8 \%$ \\
\hline Use if convenient & $79.7 \%$ & $72.2 \%$ & $82.1 \%$ & $64.5 \%$ & $73.1 \%$ & $69.1 \%$ \\
\hline Not use & $9.9 \%$ & $12.0 \%$ & $9.7 \%$ & $19.2 \%$ & $8.3 \%$ & $14.1 \%$ \\
\hline
\end{tabular}

tion, as shown in Table Table 2, the questionnaire was collected with the high ratio.

Table 3 shows the ratios of daily transportation means of seniors (over 60) and nonseniors in each residential area. As shown in Table 3, the ratios of using a private car are higher than others in all residential area, and especially, these ratios in Ayagaoka are extremely high. The data in Table 3 suggest that the use of one's private car is not easy for seniors compared with non-seniors. The conversion from using a private car to a public transportation facility will further progress with aging. Therefore, examining the ideal state of current transportation service and its improvement including the consideration of future conditions would be important. Based on the current situation as shown in Table 3 , resident's consciousness about current transportation service was analyzed, and its improvement measure was examined. Table 4 shows satisfaction level with transportation of seniors and non-seniors in each residential area. From Table 4, we can see the fact that seniors had not been satisfied with the current transportation service than non-seniors, but these ratios were different depending on the residential area. Among these residential areas, transportation service including public transportation in Misuzugaoka housing estate is relatively satisfactory, but there is a large difference in the service level within the same residential area. As this reason, the differences of distance from each resident's house to a bus stop are considered to be a critical issue. Differences of distance to a bus stop in the other residential areas are smaller than Misuzugaoka's one, but the residential areas except Misuzugaoka are not superior in terms of other service levels of transportation. The reason that Ishiuchi region had the most dissatisfaction would be due to the lowest transportation service and the fastest aging area than the others. The order from highest of aged population is Ishiuchi region, Misuzugaoka housing estate, and Ayagaoka housing estate, but the order is not same with the order of satisfaction as shown in Table 4. As shown above, we could understand that the current state of transportation service appeared in the evaluation of the satisfaction.

Table 5 shows the ratios of necessary things for reducing frustration on transportation. 
Comparing with two housing estates, there were more requests for increasing bus stop in Misuzugaoka than Ayagaoka; on the other hand, inhabitants in Ayagaoka desired to increase bus service (the number of buses) more than Misuzugaoka. The ratio of increasing bus service in Ishiuchi region was approximately $80 \%$, and the value is extremely high. Same with the consideration in Table 4, these results would suggest that the results were strongly affected by the current condition of transportation service. In any residential area, seniors tended to require the improvement of bus service. But, there is a possibility that these seniors have also desired a convenient and accessible transportation service different from a typical bus.

As mentioned above, we can see the difficulty in the everyday movement of inhabitants in these residential areas. Our survey unveiled the situation that many of the residents who intend to go out had strongly depended on their private car due to the reason that there had been few public bus transportation near their region. Especially, the extremely low service level of public transportation, e.g., there are no bus routes within reasonable walking distance from some areas, was also confirmed. Most of the residents in this type of area had disgruntled about the service level of public transportation more than the other regions. However, introducing a public transport service is considered to be unrealistic because there are only a few residents in such areas and such a surrounding is unprofitable. Thus, as a future research subject, the authors have started to examine a realistic plan to improve the service level of transportation at depopulated area by introducing a new kind of transportation service, such as a ride-sharing bus, a demand responsive bus, or a community bus. The authors have examined a possibility of the ride-sharing bus as an improvement idea of public transportation, which travels throughout the residential area and also stops by main places of transportation including a bus stop, a shopping store, and a rail station, and confirmed the potential from the interview to the residents. Table 6 shows the resident's interest in a community-based new transportation means (ride-sharing bus). As shown in Table 6, a lot of positive replies were obtained in all residential areas, and especially, seniors tended to be higher than non-seniors.

\section{Proposal}

\subsection{Ideal State on Transportation in Itsukaichi District}

Based on the previous works, we examine the ideal state on transportation in Itsukaichi district as follows.

1. In the aging housing estates at slope area, the utilization ratio of the private car is high; on the other hand, the satisfaction level with current public transportation level is low. Some of the residents desire the improvement of its situation, so a service/a system which can solve the dissatisfaction of public transportation is deemed necessary.

2. Currently, the service level of the bus has widely differed according to the surrounding of the residential area. Some of the transportation service readily available from each resident's house should be examined.

3. In the housing estate where the majority of its residents are not aging, a group of residents not interested in the service of public transportation strongly depends on their private car. They can select any transportation means, so a new transportation service should include the residents in this group to establish it as a business. 
4. In the housing estate similar with the above item, there is a possibility that the residents now strongly depending on their private car use another transportation means due to the change of their demand for transportation. Therefore, a new transportation service should be designed for not only aging residents but also others based on the long-term strategic approach.

In many cases, introduction and operation of a new public transportation service or a new bus route are possibly difficult because of financial reasons and institutional/systemic issues. A new transportation service should be designed and accepted by the workshop centering on local people. Moreover, the long-term effort aiming at the improvement of regional traffic convenience including the cooperation with local government would be examined at an early stage though the collaboration is a future challenge.

If a new public transportation service is introduced, to keep going as a business, the manager of this service should ensure a certain number of regular customers. To do this, the manager should promote the use of residents who can select some transportation means and will probably use if they feel it convenient. Concretely, the participation of non-senior residents who are satisfied with their private car is said to be surely essential to put the new service on track to success. At present, the usage frequency of private car is extremely higher than other transportation means, but the resident's main means of transportation will change to a public transportation facility with the progress of aging. The ideal state of regional public transportation should be examined by a field work before the peak of aging. To conduct a challenge of implementing a new public transportation service in the real field, utilizing resident's private car as a transportation means is considered to be effective in light of high car ownership rate. To enhance the participation of residents with private car, the system should present some benefit for residents who hope to provide their car. On this point, this paper considers that an efficient method to realize the idea of a new transportation service would be the sharing of resident's move with mainly utilizing private car. Besides, Web technology is considered to be suitable for providing an opportunity to share each resident's schedule to move. With the Web feature, matching a resident, who will move to his/her destination by one's transportation mean (a motorcycle or a car), with another resident, who wants to move but does not have a transportation means, will be easily realized. The matching generated by the new transportation service is expected to enhance people's relationship building and the regeneration of local community and these are assumed as a significant value to the improvement of living environment.

\subsection{Concept}

The concept of the proposed system is shown in Fig. 2. The structure of the proposed system in this study follows the device configuration [5] already published as a patent. The proposed system creates an opportunity of encounter for move-sharing between two or more local people. With the encounter, for example, a person, who has no daily transportation means but wants to go out, can find a person, who lives near this troubled person and can move freely such as by his/her motorcycle or car. The main aim of the proposed system is to support to bring local people together with someone's move to help each other's needs related to the movement in everyday life. The proposed system assumes two kinds of move-sharing: the one is ride-sharing where two or more residents go somewhere together by a resident's car after adjusting each one's schedule, and the other is conveyance where a resident helps another resident's conveyance while his/her moving. These features 


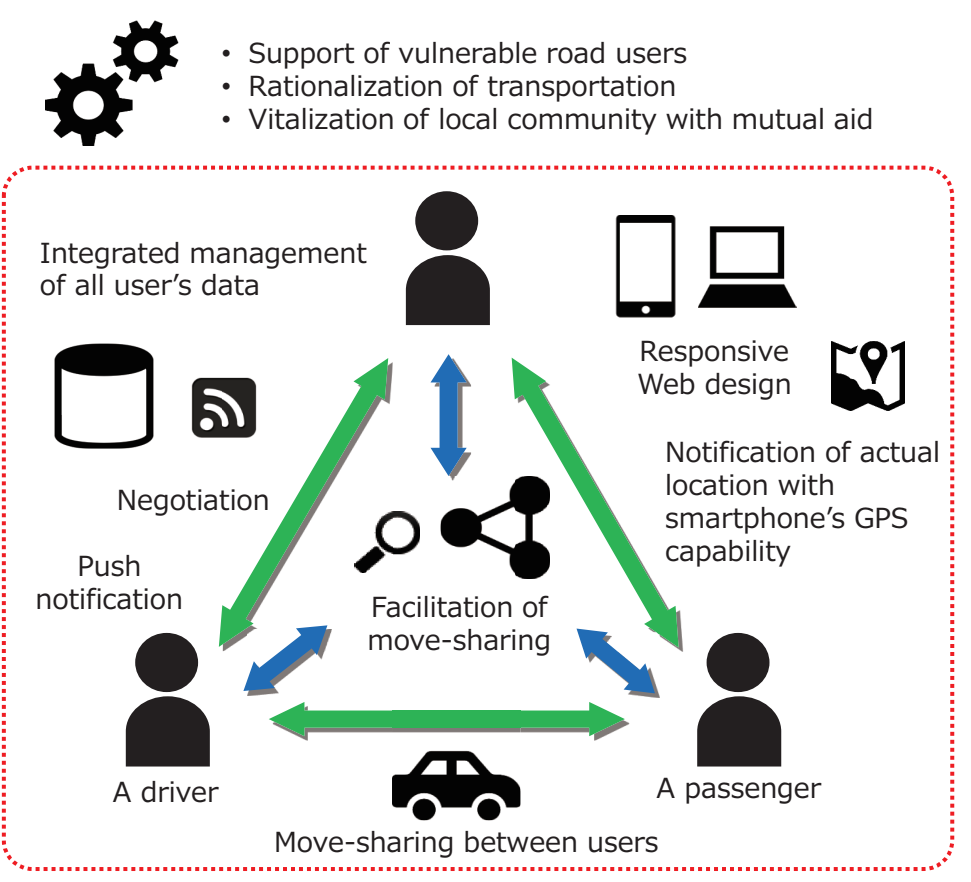

Figure 2: The concept of the proposed system

will create an opportunity for ride sharing for a short trip such as a move to a city center, and to facilitate someone's request and acceptance of the transportation of luggage while a user moves. The proposed system can promote the rationalization and efficiency in the movement of people and goods. Furthermore, Since the proposed system encourages the meetings of each local resident, the authors expect that the proposed system can contribute to reproducing a local community.

The proposed system provides primary two functions, negotiation, and schedule sharing, and they will support the cooperation between local community residents easily. For example, with the proposed system, As the types of the demands, the one may be mainly ride-sharing with the other resident's mobility, and the other may be the conveyance of luggage from residential areas to a place near another resident's destination or vice versa. The flow of the move-sharing is, firstly, a resident with a transportation problem called as "client" posts a request to a system. For example, a resident who has no transportation means for going out or needs assistance for a conveyance of daily necessaries asks for his/her help by inputting its detail to the system. Secondly, if another user, called as "server", who has a willingness to accept another resident's help finds the details of another resident's request such as conditions and personal information and thinks it acceptable, a resident as the server can contact a resident as the client by using direct message function. After the negotiation with the direct message function, a move-sharing will be done if they reach an agreement.

Each server can get the countervalue to assistance in a different way from money (fare) because a fare is unreceivable except the approval by the Minister of Land, Infrastructure, Transport and Tourism. Then, the proposed system gives an incentive, called "local point" corresponding to the charge of effort from the server. Each user can exchange the local point to a local shopping center's gift certificate or can receive a service in the local area by using it. The proposed system is operated by collecting the system usage fee from each 
user, where the price is proportional to the number of requests.

\subsection{Development of Organizational Frameworks for Solving Regional Trans- portation Problem}

The area of Itsukaichi district has played an important role as a bedroom suburb of Hiroshima City, where various service industries are accumulating on the central part located on the flat ground. From the second half of the 1970s to around 2000, some new towns (housing estates) were built at the slope area relatively far from the central part of the district. Today, the population of Itsukaichi district is approximately 100,000, and many residents are living in these housing estates. In these housing estates, the following problems will arise for people's everyday life from the present to the near future.

- The aging will progress quickly at a certain time because their age distribution are high. Expecially the rapid aging in new towns surely appear because it is predictable from the data of their sales.

- The utilization rate of private car is high in these new towns because the use of bicycle is difficult. Therefore, the traffic problem will arise along with the progress of aging.

When the rapid aging and the unbalanced age composition continue, it becomes impossible to maintain the vitality of present Itsukaichi. In order to resolve such the problems and maintain/develop the vitalization in the local community, FIVE (Friendship for Itsukaichi Vitalization and Enrichment $)^{1}$, a non-profit organization, was organized by the volunteers for contributing to promote the public benefit of the Itsukaichi district. The present primary task of FIVE is to propose and implement the policy to activate more the commerce, the life, the education, and the traffic, which can respond to an aged society. FIVE have created the opportunity to connect an aged person to the local community and also have made the place to offer information assumed to be required for elderly people. The proposed system will be operated under the management of FIVE in the near future, and the authors will continue reporting the obtained result continuously.

\section{Discussion}

The Article 80 of the Road Transportation Act have set a specific rule that a private car must not be used for the commercial purposes of transportation. When the Act was revised in 2006, the exception rule, "however, that this does not apply to the cases where there are unavoidable circumstances, such as to ensure common welfare, or to handle emergency for disaster, and if the Minister of Land, Infrastructure, Transport and Tourism has granted approval", was added to the Article 80 of the Act. Normally, the transportation support model in this paper would be against the ACT, but if the matching of transportation is determined to be applicable to the "public welfare" in the second half of Article 80, it is quite probable that its steering will be approved. Additionally, as there is the description in the Article 78 (fare-paying conveyance) and Article 79 (registration), "Those who intend to carry out the fare-paying conveyance with a private car shall obtain a registration from the Minister of Land, Infrastructure, Transport and Tourism", feasibility of the transportation support business is considered to be enough if NPO is this parent organization. Therefore, the operation of the proposed model is feasible because the primary objective is to support

\footnotetext{
${ }^{1}$ FIVE, http://www.city.hiroshima.lg.jp/www/contents/1384995381935/
} 
the local community and NPO mainly organizes this steering. Behind the above revisions, there was probably a circumstance where local governments led the revision of the Act in order to obtain a chance to operate transport business by themselves, available by long-term care insurance, due to the increase of withdrawal of private bus companies at underpopulated area. Additionally, the government council on national strategic special zones held at October 2015 instructed a consideration of deregulation, so an environment to promote the proposed model is considered to be now being developed. Therefore as future works, firstly the legal problem of the transportation support business must be clarified. Secondly, since another NPO might have provided a similar service to this study, it is necessary to pursue an investigation of the cases of transportation support business in other regions.

\section{Conclusion}

This paper gave the detailed description of the scheme of transportation support model shown by our previous work and developed its prototype system. The core of the proposed model is matching which helps to create an opportunity for ride sharing for a short trip such as a move to a city center, and to facilitate someone's request and acceptance of the transportation of luggage while a user moves. The proposed system will support the cooperation between local community residents easily, and is expected to enhance people's relationship building and the regeneration of local community. In the future, the pair of move-sharing will be automatically decided, and the result is provided to each user's smartphone with push notification.

\section{Acknowledgment}

This work was partly spported by Japan Society for the Promotion of Science, Grant-in-Aid for Scientific Research(C), No.15K00770 and FIVE, Non-Profit Organization.

\section{References}

[1] Banai-Kashanai, A.R., Toward a Synthetic Measure of Good Settlement Form" Environment and Planning B, 15, pp.399-412 (1988).

[2] N. Ohigashi, A. Tanaka and S. Watanabe, Traffic Awareness Investigation by Questionary Survey in Housing Complexs, Research bulletin of the Hiroshima Institute of Technology, Vol.43, pp.113-117 (2009), In Japanese.

[3] H. Taketa, S. Matsumoto and N. Ohigashi, A Study on Supporting Transportation for People in Slope Residential Areas at Itsukaichi, Hiroshima City, Proc. of the 16th IEEE Hiroshima Student Symposium, A-73, In CD-ROM (2014), In Japanese.

[4] S. Matsumoto, N. Ohigashi, T. Hasuike, Developing a Transportation Support System for Vulnerable Road Users in Local Community, Proc. of 2016 5th IIAI International Congress on Advanced Applied Informatics, pp.797-800 (2016).

[5] S. Matsumoto, N. Ohigashi and S. Abe, An equipment to support transportation of people and luggages in daily life, Japanese Patent Application No. 2015-160396 (2015), In Japanese. 